\title{
A INFluênCIA De PETER HÄBERLE NO CONSTITUCIONALISMO BRASILEIRO
}

GILMAR FERREIRA MENDES ${ }^{\dagger}$

\section{UM Dossiê em Homenagem A Peter HÄberle}

Palavras-Chave: Constitucionalismo; Peter Häberle; Dignidade da Pessoa Humana; Teoria do Pensamento da Possibilidade.

KEYWORDS: Constitutionalism; Peter Häberle; Human Dignity; Possibility Thinking Theory.

\footnotetext{
${ }^{\dagger}$ Ministro do Supremo Tribunal Federal do Brasil (STF). Professor de Direito Constitucional nos cursos de graduação e pós-graduação da Faculdade de Direito da Universidade de Brasília (UnB). Mestre em Direito pela UnB,1988, com a dissertação "Controle de Constitucionalidade: Aspectos Políticos e Jurídicos". Mestre em Direito pela Universidade de Münster, República Federal da Alemanha (RFA), 1989, com a dissertação "Die Zulässigkeitsvoraussetzungen der abstrakten Normenkontrolle vor dem Bundesverfassungsgericht" (Pressupostos de admissibilidade do Controle Abstrato de Normas perante a Corte Constitucional Alemã). Doutor em Direito pela Universidade de Münster, República Federal da Alemanha (RFA), 1990, com a tese "Die abstrakte Normenkontrolle vor dem Bundesverfassungsgericht und vor dem brasilianischen Supremo Tribunal Federal", publicada na série "Schriften zum Öffentlichen Recht", da Editora Duncker \& Humblot, Berlim, 1991 (a tradução para o português foi publicada sob o título Jurisdição Constitucional: o controle abstrato de normas no Brasil e na Alemanha. $4^{a}$ ed. São Paulo, SP: Saraiva, 2004).
} 


\section{SUMÁRIO:}

I. INTRODUÇÃ

II. TEORIA DO PENSAMENTO DE POSSIBILIDADES ..............................34

III. DIGNIDADE DA PESSOA HUMANA....................................................45

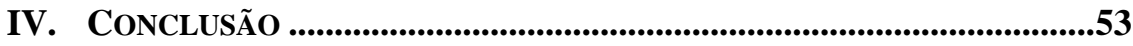

V. REFERÊNCIAS ...............................................................................54

\section{TABLE OF CONTENTS:}

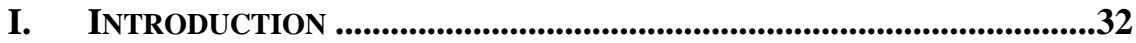

II. POSSIBILITY THINKING THEORY ..................................................34

III. DIGNITY OF HUMAN PERSON .......................................................45

IV. CONCLUSION ................................................................................53

V. REFERENCES ........................................................................54 


\section{INTRODUÇÃO}

O Prof. Dr. Dr.h.c.mult. Peter Häberle é Professor Titular aposentado de Direito Público e Filosofia do Direito da Universidade de Bayreuth, na Alemanha, e, atualmente, desempenha as funções de diretor do Instituto de Direito Europeu e Cultura Jurídica Européia, do mesmo centro universitário.

Nascido em Göppingen, Alemanha, em 1934, o Professor Peter Häberle estudou nas Universidades de Tübingen, Bonn, Montpellier (França) e Freiburg. Em sua tese de doutoramento, tratou, com brilhantismo, sobre o conteúdo essencial dos direitos fundamentais na Lei Fundamental de Bonn.

Sua obra é extensa, compondo-se de centenas de artigos e mais de vinte monografias, com aportes fundamentais para a doutrina constitucional europeia e mundial, em diversas obras, como Die Wesensgehaltgarantie des Art. 19 Abs. 2 Grundgesetz (1962) (A garantia do núcleo essencial dos direitos fundamentais na Lei Fundamental de Bonn), Öffentliches Interesse als juristisches Problem (1970) (Interesse Público como problema jurídico), Verfassungsgerichtsbarkeit (1976) (Jurisdição Constitucional), Verfassung als öffentlicher Prozess (1978) (Constituição como Processo Público), Die Verfassung des Pluralismus (1980) (A Constituição do pluralismo), Verfassungslehre als Kulturwissenschaf (1982) (Teoria da Constituição como ciência da cultura), Das Menshenbild im Verfassungsstaat (1988) (O Homem no Estado Constitucional), dentre outras.

As duas últimas décadas têm sido marcadas pela difusão dos sistemas de jurisdição constitucional em novas democracias, principalmente na Europa oriental, Ásia e América Latina ${ }^{1}$, assim como pelo fortalecimento e consolidação do arcabouço institucional do Estado constitucional em diversos países, processos nos quais o pensamento de Peter Häberle tem contribuído de forma decisiva, como é possível observar em países como Peru, México e Argentina. ${ }^{2}$

${ }^{1}$ Cf. GINSBURG, Tom. Judicial Review in New Democracies: Constitutional Courts in Asian Cases. New York, NY: Cambridge University Press; 2003; e HIRSCHL, Ran. Towards Juristocracy: The origins and consequences of the new constitutionalism. Cambridge, MA: Harvard University Press; 2004.

${ }^{2}$ Sobre a influência da doutrina de Peter Häberle no Peru, vide: LANDA ARROYO, César. Tribunal Constitucional y Estado Democrático. Lima: Palestra; 2007. No México, vide: HÄBERLE, Peter. El Estado Constitucional. Trad. Héctor Fix-Fierro. México: Universidad Nacional Autónoma de México, 2003. Na Argentina, vide: 
No Brasil, sua contribuição tem sido inestimável para o desenvolvimento do Direito Constitucional. Desde a primeira tradução, para o português, da obra Hermenêutica Constitucional: Sociedade Aberta dos Intérpretes da Constituição - contribuição para a Interpretação Pluralista e Procedimental da Constituição" incorporada com evidente vivacidade, seja no âmbito acadêmico, por meio da vertiginosa produção bibliográfica ou da prática docente e discente nas faculdades de direito, seja pelos poderes constituídos, na forma de produção legislativa e na jurisprudência dos tribunais.

São muitos os doutrinadores brasileiros de renome que defendem a necessidade de consolidação da ideia de uma sociedade aberta de intérpretes da Constituição, formulada por Peter Häberle. Segundo essa concepção, o círculo de intérpretes da Lei Fundamental deve ser alargado para abarcar não apenas as autoridades públicas e as partes formais nos processos de controle de constitucionalidade, mas todos os cidadãos e grupos sociais que, de uma forma ou de outra, vivenciam a realidade constitucional.

No âmbito legislativo, a Lei $\mathrm{n}^{\circ} 9.868 / 99$, ao institucionalizar a figura do amicus curiae na jurisdição constitucional brasileira, representa um eloquente exemplo da forte influência da doutrina de Häberle que propugna por uma interpretação aberta e pluralista da Constituição. A propósito, ressalta-se que a participação dos amici curiae é hoje admitida não apenas no controle abstrato de constitucionalidade, mas também no

HÄBERLE, Peter. El Estado Constitucional. Trad. Héctor Fix-Fierro. Buenos Aires: Astrea de Alfredo y Ricardo Depalma; 2007. No contexto iberoamericano, há diversas traduções das obras de Peter Häberle: HÄBERLE, Peter. Retos actuales del Estado Constitucional. Trad. Xabier Arzoz Santiesteban. Õnati: Instituto Vasco de Administración Pública, 1996; HÄBERLE, Peter. La libertad fundamental en el Estado Constitucional. Trad. César Landa Arroyo. Lima: Pontificia Universidad Católica del Perú, 1997; HÄBERLE, Peter. Libertad, igualdad y fraternidad: 1789 como historia, actualidad y futuro del Estado Constitucional. Trad. Ignacio Gutiérrez Gutiérrez. Madrid: Trotta, 1998; HÄBERLE, Peter. Teoría de la Constitución como ciencia de la cultura. Trad. Emilio Mikunda-Franco. Madrid, Tecnos, 2000; HÄBERLE, Peter. La imagen del ser humano dentro del Estado constitucional. Trad. Carmen Zavala. Lima: Pontificia Universidad Católica del Perú, 2001; e HÄBERLE, Peter. Pluralismo y Constitución: estudios de Teoría Constitucional de la sociedad abierta. Trad. Emilio Mikunda-Franco. Madrid: Tecnos, 2002.

${ }^{3}$ HÄBERLE, Peter. Hermenêutica Constitucional: A Sociedade Aberta dos Intérpretes da Constituição. Contribuição para a Interpretação Pluralista e "Procedimental" da Constituição. Trad. Gilmar Ferreira Mendes. Porto Alegre, RS: Sergio Antonio Fabris, 1997. 
âmbito do controle incidental, perante os Tribunais de Justiça. ${ }^{4}$

Já no âmbito jurisprudencial, decisões proferidas pelo Supremo Tribunal Federal (STF) em tempos recentes demonstram a inestimável contribuição de Peter Häberle para o desenvolvimento da Jurisdição Constitucional brasileira.

Reconhecendo o extremo valor da construção doutrinária de Häberle, no presente artigo, busca-se expor como os pressupostos teóricos desenvolvidos pelo autor foram por recepcionados nos últimos anos. Em especial, será elucidado como o pensamento das possibilidades e a visão de Häberle acerca da dignidade da pessoa humana têm se revelado fundamentais para a interpretação construtiva da Constituição de 1988.

\section{Teoria do Pensamento de Possibilidades}

O "pensamento de possibilidades" (Möglichkeitsdenken) é um modo alternativo de interpretar o Direito Constitucional, a lógica jurídica e a teoria da argumentação. Trata-se modelo fundado na dúvida, que não pensa de forma absoluta, mas busca encontrar diversas alternativas à questão que pretende solucionar.

O pensamento de possibilidades é, para Peter Häberle, expressão, consequência, pressuposto e limite para uma interpretação constitucional aberta. ${ }^{5}$ Trata-se de pensar a partir e em novas perspectivas, questionandose: "que outra solução seria viável para uma determinada situação?"

Nesse aspecto, o professor alemão ressalta que o pensamento de possibilidades não pode ser confundido com o pensamento alternativo, para que não seja associado a conceitos mutualmente excludentes ("ou um ou outro"). ${ }^{6}$ As ideias defendidas por Häberle pressupõem análise aberta a diversos espectros de uma mesma questão. Não há apenas uma ou outra alternativa, mas, ainda, uma terceira, uma quarta e, assim, sucessivamente.

4. Nesse sentido, o art. 950, § 3º, do Novo CPC (Lei no 13.105/16) manteve a redação do art. 481, § 3º, do CPC de 1973, no sentido de que: “Remetida cópia do acórdão a todos os juízes, o presidente do tribunal designará a sessão de julgamento. $\S 3^{\circ}$ Considerando a relevância da matéria e a representatividade dos postulantes, o relator poderá admitir, por despacho irrecorrível, a manifestação de outros órgãos ou entidades".

${ }^{5}$ HÄBERLE, Peter. Die Verfassung des Pluralismus: Studien zur Verfassungstheorie der offenen Gesellschaft. Königstein: Athenäum, 1980, p. 9.

${ }^{6}$ HÄBERLE, Peter. Die Verfassung des Pluralismus: Studien zur Verfassungstheorie der offenen Gesellschaft. Königstein: Athenäum, 1980, p. 3. 
Ao ter um caráter amplamente aberto, o pensamento de possibilidades tem dupla relação com a realidade. Uma é de caráter negativo: o pensamento de possibilidades indaga sobre o também possível, sobre alternativas em relação à realidade, sobre aquilo que ainda não é real. Por outro lado, o pensamento de possibilidades depende da realidade em outro sentido: possível é apenas aquilo que pode ser real no futuro (Möglich ist nur was in Zukunft wirklich sein kann). É a perspectiva da realidade (futura) que permite separar o impossível do possível. ${ }^{7}$

A propósito, anota Häberle:

O pensamento de possibilidades é o pensamento em alternativas. Deve estar aberto para terceiras ou quartas possibilidades, assim como para compromissos. Pensamento de possibilidades é pensamento indagativo (fragendes Denken). Na res publica existe um ethos jurídico específico do pensamento em alternativa, que contempla a realidade e a necessidade, sem se deixar dominar por elas. O pensamento de possibilidades ou o pensamento pluralista de alternativas abre suas perspectivas para "novas" realidades, para o fato de que a realidade de hoje poder corrigir a de ontem, especialmente a adaptação às necessidades do tempo de uma visão normativa, sem que se considere o novo como o melhor. ${ }^{8}$

Todavia, o pensamento de possibilidades não necessita ser orientado apenas para o futuro, eis que, de acordo com o entendimento de Luhmann, "a democracia permite em todo caso manter vivas e considerar como virtualmente possíveis inclusive todas aquelas possibilidades que já foram, por qualquer motivo, desconsideradas no passado". Trata-se do que Häberle denomina pensamento da reversibilidade (de todas as possibilidades e alternativas que surjam no contexto constitucional) Gedanke der Reversibilität, Alternativen im Rahmen der Verfassung. ${ }^{9}$

Nessa perspectiva, é de se mencionar também a importância do pensamento de possibilidades para a construção de uma ordem democrática.

${ }^{7}$ HÄBERLE, Peter. Die Verfassung des Pluralismus: Studien zur Verfassungstheorie der offenen Gesellschaft. Königstein: Athenäum, 1980, p.10.

${ }^{8}$ HÄBERLE, Peter. Die Verfassung des Pluralismus: Studien zur Verfassungstheorie der offenen Gesellschaft. Königstein: Athenäum, 1980, p. 3.

${ }^{9}$ HÄBERLE, Peter. Die Verfassung des Pluralismus: Studien zur Verfassungstheorie der offenen Gesellschaft. Königstein: Athenäum, 1980, p. 5. 
A constante abertura a novas possibilidades configura fator essencial aos ordenamentos jurídicos vigentes e, nas palavras do próprio Häberle, "representa o conteúdo central dos princípios jurídico-constitucionais mais relevantes". ${ }^{10}$

Para enfatizar esse aspecto, Häberle aponta que a ideia de que a democracia pressupõe a pluralidade de alternativas é mencionada por Konrad Hesse, para quem democracia seria "pluralismo de iniciativas e de alternativas", e pela doutrina americana, que lhe confere ideais de "pluralismo e competitividade". Outro exemplo de pluralidade de alternativas associada à democracia seriam as eleições, importante forma de participação democrática. ${ }^{11}$

O pensamento de possibilidades e a pluralidade de alternativas, continua o professor:

De modo algum representam fins em si mesmo, senão apenas meios para conservar e continuamente recriar condições de liberdade para todos os cidadãos levandose em consideração a consecução de um justo e razoável equilíbrio de interesses, assim como para a salvaguarda da Constituição com o passar do tempo e para poder desenvolver os bens públicos de todo ser humano em seu próprio bem e em benefício da comunidade. ${ }^{12}$

Desse modo, uma Constituição democrática que seja pluralista é um verdadeiro "compromisso de possibilidades", uma proposta de soluções e de coexistências possíveis, que não pretende impor a força política de cima para abaixo. Gustavo Zagrebelsky compartilha desse entendimento:

Só assim poderemos ter Constituições "abertas", constituições que permitam, dentro dos limites constitucionais, tanto a espontaneidade da vida social como a competição para assumir a direção política, ambas condições para a sobrevivência de uma sociedade

${ }^{10}$ HÄBERLE, Peter. Die Verfassung des Pluralismus: Studien zur

Verfassungstheorie der offenen Gesellschaft. Königstein: Athenäum, 1980, p. 5.

${ }^{11}$ HÄBERLE, Peter. Die Verfassung des Pluralismus: Studien zur

Verfassungstheorie der offenen Gesellschaft. Königstein: Athenäum, 1980, p. 5.

${ }^{12}$ HÄBERLE, Peter. Die Verfassung des Pluralismus: Studien zur

Verfassungstheorie der offenen Gesellschaft. Königstein: Athenäum, 1980, p. 8. 
pluralista e democrática. ${ }^{13}$

Nesse contexto, os direitos fundamentais acabam por representar importante meio de alternativas e de opções, fazendo que, com eles, seja possível um pluralismo democrático. ${ }^{14}$ Liberdade é, assim, sinônimo de democracia. ${ }^{15}$ São exemplos de direitos que dão margens à busca por alternativas: liberdade de eleição, liberdade profissional, de igualdade de oportunidades ao acesso à formação escolar, liberdade de escolha de local de residência.

Com isso, e essa parece ser uma das importantes consequências da orientação perfilhada por Häberle, "uma teoria constitucional das alternativas" pode converter-se em uma "teoria constitucional da tolerância". ${ }^{16}$ Daí perceber-se também que

alternativa enquanto pensamento possível afigura-se relevante, especialmente no evento interpretativo: na escolha do método, tal como verificado na controvérsia sobre a tópica enquanto força produtiva de interpretação. ${ }^{17}$

Ainda, "para o estado de liberdade da res publica afigura-se decisivo que a liberdade de alternativa seja reconhecida por aqueles que defendem determinadas alternativas". Daí ensinar que "não existem apenas alternativas em relação à realidade, existem também alternativas em relação a essas alternativas" ${ }^{18}$

Válido ressaltar, finalmente, que o pensamento de possibilidades não significa uma teoria revolucionária, mas, sim, evolucionista. Isso porque, ao passar-se a considerar alternativas e ao abandonar-se o pensamento do "ou este ou aquele" (Entweder-oder-Denken), acaba-se bloqueando

${ }_{13}$ ZAGREBELSKY, Gustavo. El Derecho Dúctil: Ley, Derechos, Justicia. 10ª ed. Trad.

Marina Gascón. Madri: Trotta, 2011, p. 14

${ }^{14}$ HÄBERLE, Peter. Die Verfassung des Pluralismus: Studien zur

Verfassungstheorie der offenen Gesellschaft. Königstein: Athenäum, 1980, p. 6.

${ }^{15}$ HÄBERLE, Peter. Die Verfassung des Pluralismus: Studien zur

Verfassungstheorie der offenen Gesellschaft. Königstein: Athenäum, 1980, p. 6.

${ }^{16}$ HÄBERLE, Peter. Die Verfassung des Pluralismus: Studien zur

Verfassungstheorie der offenen Gesellschaft. Königstein: Athenäum, 1980, p. 6

${ }^{17}$ HÄBERLE, Peter. Die Verfassung des Pluralismus: Studien zur

Verfassungstheorie der offenen Gesellschaft. Königstein: Athenäum, 1980, p. 7.

${ }^{18}$ HÄBERLE, Peter. Die Verfassung des Pluralismus: Studien zur

Verfassungstheorie der offenen Gesellschaft. Königstein: Athenäum, 1980, p. 6. 
alguma espécie de intolerância intelectual. ${ }^{19}$

$\mathrm{O}$ pensamento de possibilidades como técnica de interpretação constitucional já foi utilizado em diversos julgados do Supremo Tribunal Federal (STF). Em várias situações, essa teoria se mostrou a alternativa mais razoável para solucionar a questão debatida.

Um caso de grande destaque, que serviu de precedente a decisões futuras, foi a apreciação dos embargos infringentes opostos na ADI $1289^{20}$ contra acórdão proferido pelo STF que declarara a inconstitucionalidade - em face do artigo 115, parágrafo único, inciso II, combinado com o artigo 94 da Constituição -, de resolução do Conselho Superior da Justiça do Ministério Público do Trabalho, que dispunha sobre a formação da lista sêxtupla em hipóteses de inexistência de membros do Ministério Público com mais de 10 anos de carreira.

Na decisão da ADI 1289, por maioria de votos, o Tribunal declarou a inconstitucionalidade da norma. Em voto-vista, Min. Carlos Velloso anotou, ao pronunciar-se pela constitucionalidade da ação, verbis:

Temos, sob nossa apreciação, um princípio, o do quinto constitucional, instituído em favor dos advogados e do Ministério Público. É dizer, a Constituição institui o princípio segundo o qual um quinto dos lugares dos Tribunais Regionais Federais, dos Tribunais dos Estados e do Distrito Federal e dos Tribunais Regionais do Trabalho será composto de membros do Ministério Público, com mais de dez anos de carreira, e de advogados de notório saber jurídico e de reputação ilibada, com mais de dez anos de efetiva atividade profissional, indicados em lista sêxtupla pelos órgãos de representação das respectivas classes (C.F., art. 94; art. 115, parágrafo único, II).

O princípio, para a sua concretização, exige a satisfação dos requisitos inscritos no art. 94 da Constituição. No que concerne aos membros do Ministério Público, são dois os requisitos: a) contarem "com mais de dez anos de carreira"; b) serem indicados em lista sêxtupla pelo órgão de representação de sua classe.

${ }^{19}$ HÄBERLE, Peter. Die Verfassung des Pluralismus: Studien zur

Verfassungstheorie der offenen Gesellschaft. Königstein: Athenäum, 1980, p. 8.

${ }^{20}$ ADI 1289, Rel. Min. Octavio Galotti, DJ de 29.05.98. 
De um lado temos, pois, o princípio constitucional, o do "quinto". De outro, os requisitos.

Surge, então, o problema.

Se não houver membros do Ministério Público com o requisito acima indicado, como compor a lista sêxtupla, a fim de realizar-se o princípio? Seria possível comporse ou complementar a lista sêxtupla com membros do Ministério Público que ainda não tenham completado dez anos na carreira?

Depois de muito meditarsobre o tema, respondo afirmativamente.

É que o princípio, o do quinto constitucional, constitui a premissa maior. É certo que o requisito do tempo na carreira o embasa. Este, entretanto, há de ceder no momento em que a realização do princípio possa não ocorrer por falta de membros do Ministério Público que o satisfaçam. Temos informações seguras no sentido de que em diversos TRTs, em razão do deferimento da cautelar, suspendendo a eficácia da resolução objeto desta ação, há vagas de juízes do Ministério Público que estão ocupadas por juízes de carreira. Segundo um dos memoriais que nos foi oferecido, isto estaria ocorrendo relativamente a quatorze vagas dos TRTs. No memorial que nos foi apresentado pelo ilustre advogado Orlando Vaz Filho, está consignado, ademais, com a prova do afirmado - declaração fornecida pelo Sr. Sérgio da Costa e Silva, Diretor da Divisão do Pessoal da ProcuradoriaGeral do Ministério Público do Trabalho - que "contam registrados 379 (trezentos e setenta e nove) Membros em efetivo exercício neste Ministério Público do Trabalho, sendo que 43 (quarenta e três) constam com mais de 10 (dez) anos de efetivo exercício na carreira".

Assim sendo, se não for permitida a inclusão, na lista sêxtupla, de membro do Ministério Público com menos de dez anos de carreira, ter-se-á: ou a não realização do princípio constitucional do quinto, assim descumprindo-se o que a Constituição quer e determina (C.F., art. 94), ou o não cumprimento do segundo 
requisito, o da lista sêxtupla, vale dizer, com a feitura desta apenas com um ou dois nomes. De um modo ou de outro a ofensa à Constituição é grave: primeiro: a não realização do princípio constitucional do quinto torna irregular a composição do Tribunal e chega a por em dúvida a perfectibilidade de suas decisões; segundo, a não observância da lista sêxtupla, para o fim de realizarse o princípio do quinto constitucional, implica ofensa a princípio outro: o de que o Tribunal, que deve fazer a redução da lista sêxtupla para lista tríplice tem inibida ou mitigada a prerrogativa de escolha que lhe conferiu a Constituição; e se a lista que deveria ser sêxtupla passou a ser, na origem, tríplice, então o Tribunal não tem escolha nenhuma; e se a lista, que na origem deveria ser sêxtupla, mas que contém apenas um nome ou dois nomes, então teríamos duas ofensas, ao mesmo tempo, à Constituição: nem o Tribunal nem o Presidente da República poderiam exercer à prerrogativa constitucional de escolha (C.F., parágrafo único do art. 94). (fls. 150/153)

Em seguida, concluiu:

É de ver-se, portanto, que o ato normativo objeto desta ação impede a ocorrência de ofensas maiores à Constituição. Esclareça-se, no caso, que o referido ato normativo garante a inclusão na lista sêxtupla de procurador com dez anos na carreira - 'ficando garantida na lista sêxtupla as vagas dos procuradores com 10 (dez) anos'. Preserva-se, portanto, tanto quanto possível, a norma do art. 94 da Constituição Federal.

Tendo em vista as consequências da decisão, a Procuradoria Geral da República opôs embargos infringentes, cuja relatoria coube ao Min. Gilmar Mendes. ${ }^{21} \mathrm{O}$ relator indicou que um dos princípios constitucionais para a composição de órgãos judiciais seria a observância do quinto constitucional. A não satisfação desse princípio configuraria, portanto, um desvalor que certamente não encontra respaldo na estrutura constitucional, tal como anotado no voto do Ministro.

Ademais, o voto observou que, ao consagrar o critério da lista sêxtupla

${ }^{21}$ ADI-EI 1.289-4/DF, Rel. Min. Gilmar Mendes, julg. 3.4.2003. 
composta por procuradores que ainda não preenchiam o requisito temporal, no caso de falta de membros habilitados, a resolução do Conselho Superior da Justiça do Ministério Público do Trabalho referida atendeu a um outro valor, igualmente importante para o texto constitucional: o respeito à liberdade de escolha por parte do Tribunal e do próprio Poder Executivo.

Do contrário, restaria prejudicado o equilíbrio que o texto constitucional pretendeu formular para o sistema de escolha: participação da classe na formação da lista sêxtupla; participação do Tribunal na escolha da lista tríplice e participação do Executivo na escolha de um dos nomes. A formação incompleta da lista sêxtupla ou até mesmo o envio de um ou dois nomes que preenchessem todos os requisitos constitucionais acabaria por afetar o modelo original concebido pelo constituinte, reduzindo ou eliminando a participação do Tribunal e do Executivo no processo de escolha.

Desse modo, o Min. Gilmar Mendes considerou que, entre as interpretações cogitáveis, pareceu que aquela que mais se aproximava desse pensamento de possibilidades, na espécie, foi exatamente a perfilhada no voto do Min. Carlos Velloso, que logrou realizar os elementos normativos em eventual tensão dialética sem comprometer aspectos fundamentais da complexa decisão constitucional.

Segundo o relator, muito mais distante da vontade constitucional seria a composição do Tribunal sem a participação dos integrantes do Ministério Público, significa dizer, sem a observância do princípio do quinto constitucional na espécie. Da mesma forma, haveria de revelar-se distante do texto constitucional a composição da lista com número inferior ao estabelecido constitucionalmente, afetando o modelo já restrito de liberdade de escolha. Com base nesse entendimento, o Tribunal aceitou os argumentos do voto relator do Min. Gilmar Mendes e houve por bem superar o entendimento anterior e acolher os embargos infringentes.

Outro julgado que evidencia a ideia de omissão ou lacuna constitucional apta a justificar interpretação compreensiva do texto constitucional e das situações jurídicas pré-constitucionais foi o do Recurso Extraordinário no $147.776^{22}$, de relatoria do Min. Sepúlveda Pertence. A ementa do acórdão revela, por si só, o significado da decisão para a versão brasileira do pensamento de possibilidades:

Ministério Público: Legitimação para promoção, no juízo cível, do ressarcimento do dano resultante de

${ }^{22}$ RE 147.776-8, Rel. Min. Sepúlveda Pertence, julgado em 19.5.1998.

2 JOURNAL OF INSTITUTIONAL STUDIES 1 (2016) 
crime, pobre o titular do direito à reparação: C. Pr. Pen, art. 68, ainda constitucional (cf. RE 135.328): processo de inconstitucionalização das leis.

1. A alternativa radical da jurisdição constitucional ortodoxa entre a constitucionalidade plena e a declaração de inconstitucionalidade ou revogação por inconstitucionalidade da lei com fulminante eficácia ex tunc faz abstração da evidência de que a implementação de uma nova ordem constitucional não é um fato instantâneo, mas um processo, no qual a possibilidade de realização da norma da constituição - ainda quanto teoricamente não se cuide de preceito de eficácia limitada - subordina-se muitas vezes a alterações da realidade fáctica que a viabilizem.

2. No contexto da Constituição de 1988, a atribuição anteriormente dada ao Ministério Público pelo art. 68, C. Pr. Penal - constituindo modalidade de assistência judiciária - deve reputar-se transferida para a Defensoria Pública: essa, porém, para esse fim, só se pode considerar existente, onde e quando organizada, de direito e de fato, nos moldes do art. 134 da própria Constituição e da lei complementar por ela ordenada: até que - na União ou em cada Estado considerado -, se implemente essa condição de viabilização da cogitada transferência constitucional de atribuições, o art. 68, C. Pr. Pen será considerado ainda vigente: é o caso do Estado de São Paulo, como decidiu o plenário no RE $135.328 .{ }^{23}$

Também aqui se identificou uma incompletude no texto constitucional, que, ao outorgar a atribuição de assistência judiciária às defensorias públicas, não ressalvou as situações jurídicas consolidadas de maneira diversa no direito pré-constitucional - ausência de cláusula transitória -, especialmente naquelas unidades federadas que ainda não haviam instituído os órgãos próprios de defensoria. Destarte, a justificativa para a mantença do direito pré-constitucional fez-se com base numa disposição transitória implícita, que autorizava a aplicação do modelo legal pré-constitucional até a completa implementação do novo

${ }^{23}$ RE 147.776-8, Rel. Min. Sepúlveda Pertence, Lex-JSTF, 238, p. 390.

2 JOURNAL OF INSTITUTIONAL STUDIES 1 (2016) 
sistema previsto na Constituição.

Assim, pareceu legítimo admitir que a regra constitucional em questão continha uma incompletude: a não-regulação das situações excepcionais existentes na fase inicial de implementação do novo modelo constitucional. Não tendo a matéria sido regulada em disposição transitória, pareceu adequado que o próprio intérprete pudesse fazê-lo em consonância com o sistema constitucional, enquanto não estivessem devidamente instaladas as defensorias públicas.

Além dos julgados destacados, é de ressaltar ainda a recepção da teoria do pensamento do possível em caso marcante da jurisprudência do Tribunal Superior Eleitoral (TSE).

No Processo Administrativo no 18.483/ES, indagou-se se o dispositivo do Código Eleitoral que desobriga o alistamento eleitoral dos "inválidos" (expressão utilizada no dispositivo legal), estaria ainda em vigor, em face da disciplina constitucional conferida à matéria pelo art. $14, \S 1$, inciso II, da $\mathrm{CF} / 88$, que faculta o alistamento e o voto apenas aos analfabetos, aos maiores de setenta anos e aos maiores de dezesseis e menores de dezoito anos.

Os primeiros votos no processo concluíram pela obrigatoriedade do alistamento e do voto aos portadores de deficiência. Entenderam que a atual Constituição disciplinou, taxativamente, as hipóteses nas quais o alistamento e o voto seriam facultativos. Considerou-se, portanto, que a norma do Código Eleitoral não havia sido recepcionada pela Constituição Federal de 1988. ${ }^{24}$ Retomado o julgamento em 2004, o novo relator, Ministro Barros Monteiro, acompanhou os votos proferidos anteriormente, concluindo também pela não recepção do dispositivo.

O Ministro Gilmar Mendes pediu vista do processo e, em seu voto, aplicou a teoria do pensamento do possível para considerar que o legislador constitucional, ao facultar o voto aos maiores de setenta anos, atentou, certamente, para as prováveis limitações físicas decorrentes da sua idade, de modo a não transformar o exercício do voto em transtorno ao seu bem-estar. Nesse sentido, foram feias as seguintes ponderações:

É certo também que algumas pessoas apresentam

${ }^{24}$ Em sessão de 13.03.01 votou o ministro Garcia Vieira, relator à época. Após o voto do Relator, pediu vista o ministro Fernando Neves que, ao levar o feito a julgamento na sessão de 22.03.01, lembrou que as Constituições de 1946 e de 1967 traziam disposições expressas acerca da possibilidade de exceções à obrigatoriedade do alistamento. $\mathrm{Na}$ sequência, pediu vista o ministro Nelson Jobim. Continuando o julgamento, em 12.02.04, votou o senhor ministro Barros Monteiro, novo relator, que acompanhou os votos proferidos anteriormente.

2 JOURNAL OF INSTITUTIONAL STUDIES 1 (2016) 
deficiências que praticamente tornam impossível o exercício de suas obrigações eleitorais, tais como os tetraplégicos e os deficientes visuais inabilitados para a leitura em braile. Todos eles podem encontrar-se em situação até mais onerosa do que a dos idosos.

Ressalte-se que nem todas as salas de seções de votações têm acesso adequado para deficientes. E não se cuida de problema que possa ser superado de imediato ou que dependa, como alguns sustentaram de simples manifestação de vontade política.

Portanto, a solução que mais parece se aproximar desse "pensamento do possível", na espécie, é exatamente a que faculta o alistamento eleitoral e o voto aos cidadãos com deficiências que impossibilitam ou tornam assaz oneroso o exercício de suas obrigações eleitorais.

Muito mais distante da vontade constitucional, em todos os seus sentidos, seria obrigar a pessoa portadora de deficiência, inabilitada ao sufrágio, a deslocar-se para sua sessão de votação e submetê-la à experiência frustrante de não conseguir exercer os elementares direitos de cidadania, ou, ainda, de fazê-lo com enorme sacrifício.

Daí ter considerado que o "pensamento do possível", no Direito Constitucional, autorizava, também aqui, uma interpretação compreensiva que permita ampliar as hipóteses de alistamento facultativo a essas estritas hipóteses.

Esses exemplos diagnosticam como o pensamento do possível constitui relevante instrumento para a resolução de casos em que valores constitucionais devem ser sopesados em situações extremas. Nessas hipóteses, a jurisprudência pátria tem se mostrado cada vez mais receptiva às teses de Häberle, reconhecendo a sua relevância para o nosso Direito.

Além das aplicações jurisprudenciais do pensamento do possível, a influência de Häberle também é perceptível no tratamento conferido pelo constitucionalismo brasileiro ao princípio da dignidade da pessoa humana, conforme será demonstrado no próximo tópico. 


\section{Dignidade Da Pessoa Humana}

De amplo conhecimento, a Lei Fundamental alemã, de 1949, marcou a transição da dignidade humana como valor filosófico-teológico para textos juridicamente vinculativos. ${ }^{25} \mathrm{O}$ conceito de dignidade da pessoa humana atravessou dois mil e quinhentos anos de história da filosofia, ganhou variadas configurações nas mais diversas tradições filosóficas ${ }^{26} \mathrm{e}$ acabou por ser transformado em preceito constitucional supremo em resposta aos horrores e séries de violações ocorridas na Segunda Guerra Mundial.

Já na Constituição de Weimar havia menção à dignidade humana, no art. 151, III, que dispunha

a disciplina da atividade econômica deve corresponder aos princípios da justiça, com vista a assegurar uma existência humana digna para todos. Nesses limites assegurar-se-á a liberdade econômica aos indivíduos.

Mesmo que a dignidade não ocupasse lugar de destaque no texto de 1919, Häberle indica que esta estava a delimitar, ainda que em um campo específico, a liberdade econômica individual. Esse dispositivo serviu de paradigma para as Constituições estaduais alemãs pós 1945 e $1989^{27}$, e alcançou seu patamar máximo no art. 1ํㅡ, I da Lei Fundamental, que dispõe que: "A dignidade da pessoa humana é intocável. Observá-la e protege-la é dever de todos os poderes estatais."

A partir daí diversas Constituições no mundo também passaram a alocar a dignidade humana em especial hierarquia. O Brasil, em 1988, seguindo igualmente o exemplo das Constituições portuguesa, de 1976, e espanhola, de 1978, definiu, em seu art. 1ํㅡㄴ inciso III, que a

${ }^{25}$ HÄBERLE, Peter. A dignidade humana como fundamento da comunidade estatal. In: Ingo Wolfgang Sarlet (Org.). Dimensões da Dignidade: Ensaios de Filosofia do Direito e Direito Constitucional. 2ª ed. Porto Alegre, RS: Livraria do Advogado, 2009, p. 75 .

${ }_{26}$ PIEROTH, Bodo; SCHLINK, Bernhard. Direitos Fundamentais. São Paulo, SP: Série IDP/Editora Saraiva, 2012, p. 158-159

${ }^{27}$ HÄBERLE, Peter. A dignidade humana como fundamento da comunidade estatal. In: Ingo Wolfgang Sarlet (Org.). Dimensões da Dignidade: Ensaios de Filosofia do Direito e Direito Constitucional. 2ª ed. Porto Alegre, RS: Livraria do Advogado, 2009, p. 48.

2 JOURNAL OF INSTITUTIONAL STUDIES 1 (2016) 
República Federativa do Brasil constitui-se em Estado Democrático de Direito e tem como fundamento a dignidade da pessoa humana, ao lado da soberania, cidadania, valores sociais do trabalho e da livre iniciativa e do pluralismo político.

Ao consagrar a dignidade da pessoa humana como um dos fundamentos do Estado Democrático de Direito, o constituinte acabou por "reconhecer categoricamente que é o Estado que existe em função da pessoa humana, e não o contrário, já que o ser humano constitui finalidade precípua, e não meio da atividade estatal" 28 . Nas palavras do nosso homenageado, o ponto de partida para qualquer reflexão sobre a constituição, e sobre qualquer desenvolvimento de uma Constituição liberal, é o homem e sua dignidade. ${ }^{29}$

Note-se que tanto a Lei Fundamental quanto a Constituição brasileira de 1988 especificam a dignidade humana como fundamento máximo de seus Estados Constitucionais já no primeiro artigo. Esse fato indica o simbolismo que envolve o tema, questão muito cara à doutrina do constitucionalista germânico.

Em relação ao tema, merece destaque o artigo de Häberle intitulado Die Menschenwürde als Grundlage der Staatlichen Gemeinschaft, "A dignidade humana como fundamento da comunidade estatal", que já tem tradução para as línguas espanhola e portuguesa.

Häberle entende que mencionar a dignidade humana no preâmbulo ou no início da Constituição concede singular significado a esse princípio. E complementa:

Uma Constituição que, de início, menciona a dignidade humana como um dos seus princípios supremos, devese preocupar com essa dignidade, seja como um objetivo pedagógico - desde as escolas até regulamentação de atividade de radiodifusão - ainda que o objetivo pedagógico não esteja explicitamente mencionado no

28 SARLET, Ingo Wolfgang. Dignidade da Pessoa Humana e Direitos Fundamentais na Constituição Federal de 1988. 9ª ed. Porto Alegre, RS: Livraria do Advogado, 2011, p. 80 .

${ }^{29}$ HÄBERLE, Peter in VALADÉS, Diego (Org.). Conversas acadêmicas com Peter Häberle. Trad. Carlos dos Santos Almeida. São Paulo, SP: Série IDP/Editora Saraiva, 2009. 
texto constitucional. A Constituição assume esse compromisso a si própria ao prever textualmente a dignidade humana. ${ }^{30}$

Nesse sentido, Peter Häberle ressalta a importância da socialização cultural, para ele indispensável, que deve começar na família e deve incluir "metas educacionais para inculcar a dignidade humana, tolerância, respeito às minorias e respeito mútuo pela igualdade dos direitos fundamentais, já comum em estados alemães" ${ }^{31}$

Destaque-se que, no direito internacional, as referências à dignidade humana encontram-se, sobretudo, nos preâmbulos, como na Carta das Nações Unidas, de 26 de junho de 1945, no qual consta:

Nós, os povos das Nações Unidas - afirmamos com firmeza nossa crença nos direitos fundamentais do Homem, na dignidade e no valor da personalidade humana e no compromisso de renovadamente fortalecelos.

E também em relação aos preâmbulos temos os ensinamentos de Häberle, para quem estes são uma profissão de fé de uma religião civil da comunidade política. Seu conteúdo indica as posturas valorativas, ideais, convicções do Estado. ${ }^{32}$

A dignidade humana está mencionada nos preâmbulos de algumas das Constituições dos 27 estados federais brasileiros, assim como nas de alguns Länder. Todavia, assim como na Alemanha, o que mais se destaca é a referência à dignidade humana a títulos mais específicos de direitos fundamentais, como em dispositivos relacionados à saúde ou à ordem econômica.

Na Constituição Federal brasileira, a dignidade humana não está prevista apenas no art. $1^{\circ}$, III, mas ainda em três outras passagens. $\mathrm{O}$ art. $226, \$ 7^{\circ}$, que trata da família, base da sociedade, relaciona a dignidade

${ }^{30}$ HÄBERLE, Peter. A dignidade humana como fundamento da comunidade estatal. In: Ingo Wolfgang Sarlet (Org.). Dimensões da Dignidade: Ensaios de Filosofia do Direito e Direito Constitucional. 2ª ed. Porto Alegre, RS: Livraria do Advogado, 2009, p. 49 .

${ }^{31}$ HÄBERLE, Peter in VALADÉS, Diego (Org.). Conversas acadêmicas com Peter Häberle. Trad. Carlos dos Santos Almeida. São Paulo, SP: Série IDP/Editora Saraiva, 2009.

${ }^{32}$ HÄBERLE, Peter. El Estado Constitucional. Trad. Héctor Fix-Fierro. México: Universidad Nacional Autónoma de México, 2003, p. 274-285. 
humana ao planejamento familiar. De acordo com o dispositivo:

Fundado nos princípios da dignidade da pessoa humana e da paternidade responsável, o planejamento familiar é livre decisão do casal, competindo ao Estado propiciar recursos educacionais e científicos para o exercício desse direito, vedada qualquer forma coercitiva por parte de instituições oficiais ou privadas.

Tem-se aqui, de certa forma, a ideia de Häberle de que dignidade humana pressupõe educação e conhecimento.

Artigos que versam sobre criança e adolescentes e proteção aos idosos fazem menção à dignidade humana. $\mathrm{O}$ art. 227 da Constituição brasileira dispõe que:

É dever da família, da sociedade e do Estado assegurar à criança, ao adolescente e ao jovem, com absoluta prioridade, o direito à vida, à saúde, à alimentação, à educação, ao lazer, à profissionalização, à cultura, à dignidade, ao respeito, à liberdade e à convivência familiar e comunitária, além de colocá-los a salvo de toda forma de negligência, discriminação, exploração, violência, crueldade e opressão.

E o art. 230 indica que "A família, a sociedade e o Estado têm o dever de amparar as pessoas idosas, assegurando sua participação na comunidade, defendendo sua dignidade e bem-estar e garantindo-lhes o direito à vida."

Seguindo o princípio da simetria, algumas constituições estaduais brasileiras limitam-se a repetir os dispositivos do texto constitucional federal que vinculam a dignidade humana à proteção dos idosos e das crianças e adolescentes.

Todavia, assim como ocorreu na Alemanha e anotado por Häberle ${ }^{33}$, as constituições estaduais também deram especial destaque a questões de relevância local, iniciando um novo espectro de associação da dignidade humana a direitos fundamentais mais específicos à realidade regional.

${ }^{33}$ HÄBERLE, Peter. A dignidade humana como fundamento da comunidade estatal. In: Ingo Wolfgang Sarlet (Org.). Dimensões da Dignidade: Ensaios de Filosofia do Direito e Direito Constitucional. 2ª ed. Porto Alegre, RS: Livraria do Advogado, 2009, p. 82 .

2 JOURNAL OF INSTITUTIONAL STUDIES 1 (2016) 
Nesse sentido, repetem-se nos textos constitucionais estaduais brasileiros referências à aplicação da dignidade humana ao tratamento de presos, à educação e à proteção da mulher. Há casos mais específicos, como a previsão da dignidade humana como princípio da política agrícola e fundiária (Constituição do Estado da Bahia), como base do tratamento de portadores de deficiência (Constituição do Estado de Goiás) e da pesquisa tecnológica (Constituição do Estado do Rio Grande do Sul).

É surpreendente verificar, a partir das Constituições estaduais brasileiras, a multiplicidade de associações da dignidade humana a direitos fundamentais. Isso porque, como usualmente indicado pelo Tribunal Constitucional alemão, o princípio da dignidade humana é o ponto de partida de outros direitos fundamentais, ele reforça o vínculo com outros direitos. ${ }^{34}$

$\mathrm{Na}$ Alemanha, a dignidade humana aparece nas decisões do Tribunal constitucional como valor jurídico supremo, valor jurídico mais elevado, fim supremo de todo o direito, determinação da inviolabilidade da dignidade humana, que está na base de todos os direitos fundamentais.

Entretanto, "o Tribunal Constitucional maneja o art. 1ํ, I, como ponto de partida do poder estatal, sem invocar a dignidade humana de modo inflacionário, evitando sua desvalorização. Ela não é utilizada em argumentação de forma panfletária" 35 , a fim de evitar sua banalização.

Sob essa perspectiva, deve-se ver com ressalva a larga associação direta do princípio da dignidade humana aos mais variados e específicos direitos fundamentais, como ocorre em algumas constituições estaduais brasileiras, de modo que não se esvazie seu núcleo essencial. Aqui se entra em uma difícil questão da doutrina da dignidade humana: sua definição.

É verdade que a invocação frequente do princípio da dignidade humana pode levar a sua banalização. Haveria, aí, a necessidade de adaptação do conceito de dignidade humana ao nosso tempo, questão delicada, já que seus limites não podem ser muito estendidos. Esses limites são definidos com auxílio do desenvolvimento histórico-cultural

34 PIEROTH, Bodo; SCHLINK, Bernhard. Direitos Fundamentais. São Paulo, SP: Série IDP/Editora Saraiva, 2012, p. 158-159.

${ }^{35}$ HÄBERLE, Peter. A dignidade humana como fundamento da comunidade estatal. In: Ingo Wolfgang Sarlet (Org.). Dimensões da Dignidade: Ensaios de Filosofia do Direito e Direito Constitucional. 2ª ed. Porto Alegre, RS: Livraria do Advogado, 2009, p. 57.

2 JOURNAL OF INSTITUTIONAL STUDIES 1 (2016) 
da sociedade e de seus valores. ${ }^{36}$

Para Günter Dürig, considerado um dos principais comentadores da Lei Fundamental, a dignidade humana consiste no fato de que

cada ser humano é humano por força de seu espírito, que o distingue da natureza impessoal e que o capacita para, com base em sua própria decisão, tornar-se consciente de si mesmo, de autodeterminar sua conduta, bem como de formatar a sua existência e o meio que o circunda. ${ }^{37}$

Nesse aspecto, Peter Häberle reitera que a dignidade humana tem como base a referência ao outro, o reconhecimento de igualdade dos outros, o "Du-Bezug". O enunciado jurídico-fundamental da dignidade humana é comumente acompanhada de palavras como o "outro", "próximo", "irmão" - no sentido de fraternidade. A palavra-chave da dignidade humana seria a "co-humanidade comunicativa" (kommunikative Mitmenschlichkeit), que engloba a perspectiva futura e institui uma comunidade responsável com as gerações que estão por vir. ${ }^{38}$ E ele anota, também, que:

O Estado Constitucional, bem como a cláusula da dignidade humana, foram concretizados por meio de longo desenvolvimento cientifico e constitui resultado provisório - de muitos processos. Nesse sentido, a dignidade humana, situa-se no contexto dos fenômenos a serem manejados de forma interdisciplinar e científico -cultural. ${ }^{39}$

${ }^{36}$ BENDA, Ernst. The protection of human dignity (Article 1 of the Basic Law). SMU Law Review, Vol, 53, 2, 2000.

${ }^{37}$ DÜRIG, Günter apud SARLET, Ingo Wolfgang. Dignidade da Pessoa Humana e Direitos Fundamentais na Constituição Federal de 1988. $9^{\text {a }}$ ed. Porto Alegre, RS: Livraria do Advogado, 2011, p. 55. Cf. DÜRIG, Günter. Escritos Reunidos: 1952-1983. São Paulo, SP: Série IDP/Saraiva, 2016.

${ }^{38}$ HÄBERLE, Peter. A dignidade humana como fundamento da comunidade estatal. In: Ingo Wolfgang Sarlet (Org.). Dimensões da Dignidade: Ensaios de Filosofia do Direito e Direito Constitucional. 2ª ed. Porto Alegre, RS: Livraria do Advogado, 2009, p. 81

${ }^{39}$ HÄBERLE, Peter. A dignidade humana como fundamento da comunidade estatal. In: Ingo Wolfgang Sarlet (Org.). Dimensões da Dignidade: Ensaios de Filosofia do 
Essa provisoriedade não significa que não exista um conceito eterno, universal de dignidade da pessoa humana, que poderia ser aplicável a todos a qualquer tempo. Há um conceito básico, interculturalmente válido.40

Sobre a forma de construção de uma identidade humana em uma sociedade e até que ponto pode se partir de um conceito de identidade interculturalmente válido e, dessa forma, universal, Peter Häberle destaca que:

O processo de formação de identidade parece ser alcançado no âmbito de uma liberdade enquadrada em uma determinada moldura. Essa moldura é também a "superestrutura" jurídica da sociedade. Por meio dela o princípio da dignidade humana transmite ao indivíduo determinadas "concepções normativas a respeito da pessoa", que, por sua vez, são impregnadas pela cultura de onde surgiram. ${ }^{41}$

Essa moldura orientadora não é estática, "a especificidade cultural das noções de dignidade humana transforma-se, com isso, em algo culturalmente específico ao seu tempo". ${ }^{42}$

Tal questão vai ao encontro de outro famoso estudo de Häberle, o Zeit

Direito e Direito Constitucional. 2ª ed. Porto Alegre, RS: Livraria do Advogado, 2009, p. 40

${ }^{40}$ HÄBERLE, Peter. A dignidade humana como fundamento da comunidade estatal. In: Ingo Wolfgang Sarlet (Org.). Dimensões da Dignidade: Ensaios de Filosofia do Direito e Direito Constitucional. 2ª ed. Porto Alegre, RS: Livraria do Advogado, 2009, p. 79.

${ }^{41}$ HÄBERLE, Peter. A dignidade humana como fundamento da comunidade estatal. In: Ingo Wolfgang Sarlet (Org.). Dimensões da Dignidade: Ensaios de Filosofia do Direito e Direito Constitucional. $2^{\underline{a}}$ ed. Porto Alegre, RS: Livraria do Advogado, 2009, p. 79.

${ }^{42}$ HÄBERLE, Peter. A dignidade humana como fundamento da comunidade estatal. In: Ingo Wolfgang Sarlet (Org.). Dimensões da Dignidade: Ensaios de Filosofia do Direito e Direito Constitucional. 2ª ed. Porto Alegre, RS: Livraria do Advogado, 2009, p. 79. 
und Verfassung ${ }^{43}$, no qual especifica que não existe norma jurídica, senão norma jurídica interpretada, ressaltando-se que interpretar um ato normativo nada mais é do que colocá-lo no tempo ou integrá-lo na realidade pública, introduzindo, aí, o conceito de pós-compreensão (Nachverständnis), entendido como o conjunto de fatores temporalmente condicionados com base nos quais se compreende "supervenientemente" uma dada norma. A pós-compreensão nada mais seria, para Häberle, do que a pré-compreensão do futuro, isto é, o elemento dialético correspondente da ideia de pré-compreensão. ${ }^{44}$

Tal concepção permite a Häberle afirmar que, em sentido amplo, toda lei interpretada - não apenas as chamadas leis temporárias - é uma lei com duração temporal limitada. Em outras palavras, o texto, confrontado com novas experiências, transforma-se necessariamente em outro texto. A continuidade da Constituição somente será possível se passado e futuro estiverem nela associados. ${ }^{45}$

Daí que, para saber em que circunstancias a dignidade humana é violada, é preciso que esta não seja respondida em termos gerais, mas levando em consideração o caso concreto, o estado geral civilizacional e cultural de uma sociedade determina diferentes concepções e concretizações da dignidade da pessoa humana. ${ }^{46}$ Ademais, como diz o Bundesverfassungsgericht, a dignidade humana é ao mesmo tempo um princípio constitucional supremo e um direito fundamental. Com isso, não trata de uma ideia abstrata de humanidade, mas diretamente com homens e mulheres reais. ${ }^{47}$

O STF também já declarou a importância da dignidade humana em casos de sua flagrante violação. Pieroth-Schlink listam uma série de ingerências ao princípio da dignidade humana, do ponto de vista

${ }^{43}$ HÄBERLE, Peter. Zeit und Verfassung. In: Ralf Dreier; Friedrich Schwegmann (Hrsg.). Probleme der Verfassungsinterpretation: Dokumentation e Kontroverse. Baden-Baden: Nomos-Verlagsgesllschaft, 1976.

${ }^{44}$ HÄBERLE, Peter. Zeit und Verfassung. In: Ralf Dreier; Friedrich Schwegmann (Hrsg.). Probleme der Verfassungsinterpretation: Dokumentation e Kontroverse. Baden-Baden: Nomos-Verlagsgesllschaft, 1976, p.312-313.

${ }^{45}$ HÄBERLE, Peter. Zeit und Verfassung. In: Ralf Dreier; Friedrich Schwegmann (Hrsg.). Probleme der Verfassungsinterpretation: Dokumentation e Kontroverse. Baden-Baden: Nomos-Verlagsgesllschaft, 1976, p. 295-296.

${ }^{46}$ PIEROTH, Bodo; SCHLINK, Bernhard. Direitos Fundamentais. São Paulo, SP: Série IDP/Editora Saraiva, 2012, p. 161.

${ }^{47}$ BENDA, Ernst. The protection of human dignity (Article 1 of the Basic Law). SMU Law Review, Vol, 53, 2, 2000, p. 444. 
histórico-sistemático, que inclui, entre outros, a escravidão, a servidão, o tráfico de seres humanos, a tolerância da degradação em situação de abandono, a privação de toda a possibilidade de fazer valer as suas próprias necessidades e pretensões contra o Estado. ${ }^{48}$

É evidente que em casos extremos é necessário a importância suprema da dignidade humana. O exercício laboral em condições degradantes e desumanas, análogas a de escravos, foi objeto de verificação pela Corte brasileira. Justamente por se tratar de situação flagrantemente atentatório à dignidade humana, seu caráter essencial ao Estado de Direito foi duramente reiterado ao longo do julgamento. ${ }^{49}$ No caso, mencionou-se que:

É claro que o trabalho escravo é uma prática condenada pela sociedade, violadora de toda a ordem constitucional, que possui na dignidade da pessoa humana a sua norma-base (Häberle) e seu valor jurídico supremo (Dürig). Foi ressaltado, também, que é inadmissível pensar que o respectivo sistema de organização do trabalho, atividade que dignifica o homem e em que ele se aperfeiçoa completamente, possa ser concebido unicamente à luz do que tradicionalmente se passou a caracterizar como "órgãos e instituições", excluindo-se dessa relação o ator principal de todo o sistema, isto é, o homem, esse ser dotado de dignidade intrínseca. ${ }^{50}$

Desse modo, verifica-se que a acepção de dignidade da pessoa humana emoldurada na obra de Häberle guarda intrínseca relação com o conceito que atribuímos a esse princípio no constitucionalismo brasileiro.

\section{CONCLUSÃO}

Peter Häberle destaca-se, para além do inestimável cabedal jurídico, pela profundidade de seus conhecimentos filosóficos, teológicos e artísticos, os quais têm dado a este professor notável o título de um

${ }^{48}$ PIEROTH, Bodo; SCHLINK, Bernhard. Direitos Fundamentais. São Paulo, SP: Série IDP/Editora Saraiva, 2012, p. 82.

${ }^{49}$ RE 398.041, Rel. Min. Joaquim Barbosa, julgamento em 30.11.2006.

${ }^{50}$ RE 398.041, Rel. Min. Joaquim Barbosa, julgamento em 30.11.2006. 
autêntico humanista. Sua obra tem chamado a atenção pela originalidade metodológica, atualização e profundidade conceitual, que permite novas abordagens para as ciências humanas, em geral, e jurídica, em particular.

Seu pensamento constitui um arcabouço teórico fundamental para a compreensão da jurisdição constitucional brasileira. Por isso, tão oportuna se afigura a homenagem realizada pela Revista Estudos Institucionais a esse constitucionalista, que é um dos maiores pensadores do nosso tempo.

\section{REFERÊNCIAS}

BENDA, Ernst. The protection of human dignity (Article 1 of the Basic Law). SMU Law Review, Vol, 53, 2, 2000.

DÜRIG, Günter. Escritos Reunidos: 1952-1983. São Paulo, SP: Série IDP/Editora Saraiva, 2016.

GINSBURG, Tom. Judicial Review in New Democracies:

Constitutional Courts in Asian Cases. New York, NY: Cambridge University Press; 2003.

HÄBERLE, Peter. A dignidade humana como fundamento da comunidade estatal. In: Ingo Wolfgang Sarlet (Org.). Dimensões da Dignidade: Ensaios de Filosofia do Direito e Direito Constitucional. $2^{a}$ ed. Porto Alegre, RS: Livraria do Advogado, 2009.

\section{. Die Verfassung des Pluralismus: Studien zur}

Verfassungstheorie der offenen Gesellschaft. Königstein: Athenäum, 1980.

El Estado Constitucional. Trad. Héctor Fix-Fierro. Buenos Aires: Astrea de Alfredo y Ricardo Depalma; 2007. 
. El Estado Constitucional. Trad. Héctor Fix-Fierro. Ciudad do México: Universidad Nacional Autónoma de México, 2003.

Hermenêutica Constitucional: A Sociedade Aberta dos Intérpretes da Constituição. Contribuição para a Interpretação Pluralista e "Procedimental" da Constituição. Trad. Gilmar Ferreira Mendes. Porto Alegre, RS: Sergio Antonio Fabris, 1997.

. La imagen del ser humano dentro del Estado constitucional. Trad. Carmen Zavala. Lima: Pontificia Universidad Católica del Perú, 2001.

. La libertad fundamental en el Estado Constitucional. Trad. César Landa Arroyo. Lima: Pontificia Universidad Católica del Perú, 1997.

. Libertad, igualdad y fraternidad: 1789 como historia, actualidad y futuro del Estado Constitucional. Trad. Ignacio Gutiérrez Gutiérrez. Madrid: Trotta, 1998.

. Pluralismo y Constitución: estudios de Teoría Constitucional de la sociedad abierta. Trad. Emilio Mikunda-Franco. Madrid: Tecnos, 2002.

. Retos actuales del Estado Constitucional. Trad. Xabier Arzoz

Santiesteban. Õnati: Instituto Vasco de Administración Pública, 1996.

. Teoría de la Constitución como ciencia de la cultura. Trad. Emilio Mikunda-Franco. Madrid, Tecnos, 2000.

. Zeit und Verfassung. In: Ralf Dreier; Friedrich Schwegmann (Hrsg.). Probleme der Verfassungsinterpretation: Dokumentation e Kontroverse. Baden-Baden: Nomos-Verlagsgesllschaft, 1976. 
HIRSCHL, Ran. Towards Juristocracy: The origins and consequences of the new constitutionalism. Cambridge, MA: Harvard University Press; 2004.

\section{LANDA ARROYO, César. Tribunal Constitucional y Estado}

Democrático. Lima: Palestra; 2007.

PIEROTH, Bodo; SCHLINK, Bernhard. Direitos Fundamentais. São Paulo, SP: Série IDP/Editora Saraiva, 2012.

SARLET, Ingo Wolfgang. Dignidade da Pessoa Humana e Direitos Fundamentais na Constituição Federal de 1988. $9^{a}$ ed. Porto Alegre, RS: Livraria do Advogado, 2011.

SARLET, Ingo Wolfgang (Org.). Dimensões da Dignidade: Ensaios de Filosofia do Direito e Direito Constitucional. $2^{\mathrm{a}} \mathrm{ed}$. Porto Alegre, RS: Livraria do Advogado, 2009.

VALADÉS, Diego (Org.). Conversas acadêmicas com Peter Häberle. Trad. Carlos dos Santos Almeida. São Paulo, SP: Série IDP/Editora Saraiva, 2009.

ZAGREBELSKY, Gustavo. El Derecho Dúctil: Ley, Derechos, Justicia. 10ª ed. Trad. Marina Gascón. Madri: Trotta, 2011.

A Influência de Peter Häberle no Constitucionalismo Brasileiro The Influence of Peter Häberle in the Brazilian Constitutionalism

Submetido em: 2016-07-21 